TITLE:

\title{
Estimation of shear strength recovery and permeability of single rock fractures in shear-hold-shear type direct shear tests
}

\section{$\operatorname{AUTHOR(S):~}$}

Kishida, Kiyoshi; Kawaguchi, Yuta; Nakashima, Shinichiro; Yasuhara, Hideaki

\section{CITATION:}

Kishida, Kiyoshi ... [et al]. Estimation of shear strength recovery and permeability of single rock fractures in shear-hold-shear type direct shear tests. International Journal of Rock Mechanics and Mining Sciences 2011, 48(5): 782-793

\section{ISSUE DATE:}

2011-07

URL:

http://hdl.handle.net/2433/143678

\section{RIGHT:}

(C) 2011 Elsevier Ltd.; This is not the published version. Please cite only the published version.; この論文は出版社版でありません。引用の際に は出版社版をご確認ご利用ください。 
Estimation of shear strength recovery and permeability of single rock fractures in shear-hold-shear type direct shear tests

Kiyoshi Kishida, Yuta Kawaguchi, Shinichiro Nakashima, Hideaki Yasuhara

\section{Abstract}

The evolution of the long-term mechanical, hydraulic, and transport characteristics of rock fractures should be predicted in advance by considering the issue of the underground deposits of the energy byproducts of high-level radioactive waste. This paper presents slide-hold-slide direct shear-flow coupling experiments conducted for mortar and granite specimens with single fractures so as to investigate the effects of load holding on the mechanical properties of rock joints. From the experimental results, it is confirmed that the shear strength of the mortar replica specimens increases and the permeability decreases during three days of load holding. However, no significant changes are observed for the mechanical or the hydro-mechanical properties of the granite specimen even after twenty days of load holding. It is also confirmed that the shear strength of the mortar specimens increases in both short- and long-time holding cases. However, the evolution of shear strength recovery is found to be different for the two cases. This is because the dominant factor in the shear strength recovery during short-time holding may be attributed to a purely mechanical process, like creep deformation at the contacting asperities, while the shear strength recovery during long-time holding is affected by both mechanical and chemical processes like pressure solution.

Moreover, to reproduce the shear strength recovery during short-time holding, we develop a direct shear model by employing a temporal variation in the dilation that occurs during load holding. The model predictions are in relatively good agreement with the experimental observations in the range of the short-holding period.

KEYWORDS: Rock fracture, direct shear test, healing of shear strength, pressure solution, prediction model

\section{Introduction}


In nuclear waste disposal and $\mathrm{CO}_{2}$ geo-sequestration projects, it is of significant importance to discuss and evaluate the long-term changes in the mechanical and the hydro-mechanical properties of jointed rock masses. While these projects are being conducted, the hydraulic conductivity of the rock masses may change due to deformation resulting from changes in the stress distribution induced by the excavation of the underground cavern and the underground deposits of waste matter in the short-term range. Under temperature-elevated conditions, mediated by the waste disposal, the dissolution of primary minerals and the precipitation of secondary minerals in the rock may become active, and the mechanical and the hydro-mechanical properties of the rock fractures may change. Under various confining stresses, deformation induced by pressure and chemical responses occurs at several contacted asperities within the rock fractures. If the contacted asperities deform, the apertures of the fractures may close with time and the hydraulic conductivity may change. Due to these alternations in the apertures, the distribution of stress around the rock fractures will also change. Such mechanical and chemical reactions do not necessarily make a rock structure unstable. The solution matter from the contacted asperities on the rock fractures dissolves into the void water on the factures. As the dissolved matter precipitates and becomes crystal on the free surface of the rock fractures, because of an oversaturation of the solution concentrations, the volume of the apertures decreases. Consequently, the hydraulic conductivity may decrease and the strength of the rock fractures may increase.

The chemo-mechanical fluid-rock interactions, which result in a reduction in permeability and the recovery of fracture strength under hydrothermal and confining pressure conditions, have been reported for sandstone [1]. A significant strength recovery (i.e., 75\% of the initial rock strength) of the fractured sandstone is measured in a short pressure-holding period of 6 hrs. It is also reported that during the holding, the permeability of the rock fractures decreases monotonically with time. The applied confining pressure of $50 \mathrm{MPa}$ and the temperature of $927^{\circ} \mathrm{C}$ are both significantly high. This is because the deep underground conditions are being simulated during interseismic periods. Yasuhara et al. [2] reported such a strength recovery using a quartz aggregate under relatively low 
confining pressure (i.e., $5 \mathrm{MPa}$ ) and temperature (i.e., $65^{\circ} \mathrm{C}$ ) conditions, and explained that this evolution of strength may be attributed to the chemo-mechanical process of the pressure solution [3 -12]. Pressure solution involves three linked processes, namely, dissolution at the stressed interfaces of the contact area, diffusive transport of the dissolved mass from the interface to the pore space, and finally, precipitation at the less stress-free surfaces. This chemo-mechanical process may contribute to strength recovery even under relatively low stress and temperature conditions [2, 11, 12]. One of the pioneer research works in the recovery of shear strength was conducted by Dieterich [13-15]. In the cyclic process of slide and hold in friction table experiments using particle quartz, Dieterich [13] confirmed that the increments in strength recovery were apparent in the case of the longer holding period. The reasons for this phenomenon were considered to be that the contacted area on the rock surface was practically very small due to the roughness and that the contacted asperities were applied to a high level of stress. Consequently, creep deformation occurred at the contacted asperities, due to the high stress condition, and the contacted area was expanded as time-dependent [15].

In order to clarify the influence of the holding state on the shear strength in the shear process of a single rock fracture, slide-hold-slide (SHS) direct shear-flow coupling tests are carried out on single rock fractures at several confining stresses and under saturated/unsaturated conditions. This experimental work examines the influence of the chemo-mechanical effects on the evolution of shear strength in the rock fractures, and discusses the time-dependency and the stress-dependency on the shear strength recovery through the experimental results and the model prediction [16-17].

\section{Slide-hold-slide direct shear-flow coupling experiments on single fractures}

\subsection{Specimens}

Two types of specimens are employed in this study, namely, granite and mortar replica specimens. The granite is sampled from Mizunami, a city located in the middle of Japan's main island of Honshu. A single fracture is artificially created by cutting away at a granite block. Then, a 
rectangular solid is formed with a cross section of $120 \times 80 \mathrm{~mm}(80 \mathrm{~mm}$ is the flow direction) and a height of $120 \mathrm{~mm}$.

In contrast, three kinds of fractures are utilized for the mortar experiments, namely, two natural rough fractures and one artificial smooth fracture. The combination ratio of cement, sand, and water is $1: 2: 0.65$. High- and early-strength Portland cement and silica sand number 6 are used. The procedure for making the mortar replicas with the natural fracture surface roughness is as follows. Firstly, one side of the fracture is replicated using silicon rubber. Rubber gives a perfect mirror image of the fracture surface. Secondly, cement mortar is poured onto the rubber used as a mold, and the rubber is peeled off 24 hrs after the pouring step. Finally, cement mortar is again poured onto the solidified mortar. This procedure guarantees a well-matched specimen with a natural, rough fracture. The mortar specimens are cured in water for 28 days. The artificial specimens used in this research are rectangular prisms with a cross section of $80 \times 120 \mathrm{~mm}$ and a height of $120 \mathrm{~mm}$. Each specimen contains a single fracture, which is located at the center (lengthwise) of the specimen and is approximately aligned on the horizontal plane. The material properties of both the granite and the mortar specimens are shown in Table $\mathbf{1 .}$

Measuring the joint surface roughness and evaluating the contact points between two surfaces are very challenging and yet important tasks necessary to discussions on the mechanical and the hydro-mechanical behavior of rock fractures. In this paper, after presenting the shear behavior using the mechanical shear model [16-17], the $3-D$ roughness profiling system [18] is adopted to profile the joint surface roughness before and after performing the tests. This system consists of an $X-Y$ positioning table, with a positioning accuracy of $\pm 15 \mu \mathrm{m}$ and a reposting accuracy of $\pm 15 \mu \mathrm{m}$, and a laser scan micrometer, with a maximum resolution of $0.5 \mu \mathrm{m}$, a measurement allowance spot dimension of $45 \times 20 \mu \mathrm{mm}^{2}$, and a measurement range of $\pm 8 \mathrm{~mm}$. The rough joint surface is measured at $0.5 \mathrm{~mm}$ intervals. The profiling data are accumulated and fed into the computer as the digital format. Based on the digital data on joint surface roughness, Barton's JRC (Joint Roughness Coefficient) [19-20] for each specimen is calculated using the relationship between $J R C$ and $Z_{2}$ [21]. 
The calculated $J R C$ value for each specimen is also shown in Table 1, and a contour map of the joint surface roughness on one side of the granite fracture profiled by a laser scan micrometer is shown in Fig.1.

\subsection{Experimental procedure}

In order to clarify the hydraulic characteristics of a single fracture under the shear process, a shear tester is employed [18]. It has been improved by supplementing a flow system that prevents water leakage around the specimen so as to conduct permeability tests on the fracture [22]. Fig.2 shows the entire outlines of the direct shear tester and the shear box.

The shear unit of the apparatus in Fig.2 is controlled by an electric and oil pressure servo mechanism which includes a feedback system. Four items, namely, shear (horizontal) load, shear displacement, normal (vertical) load, and normal displacement, are measured in the shear unit, and the obtained data are automatically recorded in the computer. The loads are measured by two types of load cells, MTS MODEL 661,238-01 for the vertical load and TCLU-20A for the horizontal load. In the experiments, the area sheared along a single fracture decreases as the shearing process advances. In order to maintain a constant normal confining stress, the normal load is automatically adjusted by considering the reduction in shear area. Electric gap sensors, HA-162S-91108, are employed to measure both vertical and horizontal displacements.

The shear box shown in Fig.2 has the function of preventing seepage and water leak. In order to prevent water leakage, a gel sheet is inserted in the space between the specimen and the shear box as a sealant. The sheet is designed in such a way as to prevent water leakage from the gaps in both the upper and the lower shear boxes without disturbing the shear deformation, namely, without friction. The performance of the gel sheet had been confirmed in previous research work [22]. The resolution of the permeability tests is $0.05 \mathrm{cc} / \mathrm{mv}$.

\subsection{Experimental conditions}

In this paper, four kinds of specimens are employed for the slide-hold-slide direct shear and flow coupling experiments. Each specimen is listed in Table 1. The tests were performed at every 
predetermined shear displacement up to $3 \mathrm{~mm}$, keeping the constant hydraulic head at $1.0 \mathrm{~m}$ or not (dry condition) and the constant normal confining stress at 1.0, 3.0, 5.0, and 7.0 MPa. The measured parameters in these experiments are the shear displacement, the shear stress, the normal displacement, the normal stress, the discharge, and the hydraulic pressure difference under a constant shear displacement velocity of $0.1 \mathrm{~mm} / \mathrm{min}$ and various holding periods. The experimental conditions are shown in Table 2.

Before starting the direct shear tests, cyclic loading and unloading tests, called roughness stiffness loading and unloading tests, were performed three times. The normal stress for the cyclic loading and unloading ranged from 0.25 to $4.0 \mathrm{MPa}$. The objectives of the roughness stiffness loading and unloading tests are described as follows:

a) At the initial set-up of the specimen, the joint surface roughness does not match perfectly. Therefore, the match of the joint surface roughness is improved in order to allow for the application of the normal confining pressure.

b) The aperture does not become zero, although several levels of normal confining pressure are applied. In order to estimate the aperture at the initial condition, normal cyclic loading and unloading tests are carried out. Then, the relation between the normal stress and the normal displacement of a single fracture is obtained.

The shear speed of $0.1 \mathrm{~mm} / \mathrm{min}$ is employed in the shear process of each specimen. And, the flow direction for the permeability tests is in agreement with the shear direction.

\subsection{Estimation of the initial aperture}

Considering the permeability of a single rock fracture, the aperture is one of the representative factors which control the observed discharge. Dilation, which is measured in the shear process on the rock joint, is the relative vertical displacement against the initial set-up condition of the upper specimen and is not the aperture. In this research work, the geometrical (mechanical) aperture is defined as the combined value of the initial aperture and the observed dilation. The initial aperture is determined by the contact condition between the upper specimen and the lower specimen under 
various normal confining stresses before starting the shear tests. Therefore, the determination of the initial aperture plays an important role in estimating the mechanical aperture in the shear process with accuracy.

The relationship between the changes in aperture and the normal stress can be approximated using the following expression [23]:

$\sigma_{n}=\frac{v_{j} \cdot k_{n i} \cdot V_{m c}}{V_{m c}-v_{j}}$

where $\sigma_{n}, v_{j}, k_{n i}$, and $V_{m c}$ are the normal stress, the closure of the aperture, the normal stiffness of the discontinuities, and the maximum closure of the aperture, respectively. Here, Bandis et al. [23] did not account for the changes in aperture. They applied the closure of the aperture and specified that the closure of the aperture was zero at a normal stress of zero. Table $\mathbf{3}$ shows the maximum closure of the aperture, the initial aperture, and the normal stiffness of the fracture for each specimen.

\section{Experimental results and discussion}

\subsection{Granite specimen}

Fig.3(a) shows the shear stress - shear displacement and the dilation - shear displacement relations of the SHS shear experiments on the granite specimen (G-1). From the figure, the peak shear stress is $3.12 \mathrm{MPa}$ at a shear displacement of $0.12 \mathrm{~mm}$. Shear-holding at shear displacements of 2.0 and $2.5 \mathrm{~mm}$ was performed at the residual stress state for 5 and 20 days, respectively. Fig.3(b) presents an enlarged view of the shear stress curve around shear displacements of $2.0 \mathrm{~mm}$ and $2.5 \mathrm{~mm}$. A reduction in shear stress can be observed in each holding process. It is thought that this reduction occurs because the frictional force at the sliding process, $\mu_{d} \sigma_{n}\left(\mu_{d}\right.$ : coefficient of dynamic friction), is larger than that at the holding period, $\mu_{s} \sigma_{n}\left(\mu_{s}\right.$ : coefficient of static friction). On the other hand, the post-holding shear stress recovery cannot be confirmed as compared with the pre-holding recovery. The dilation and the transmissibility during the holding period are shown in 
Fig.4. It is confirmed that dilation and transmissibility are constant in the holding period.

If chemical effects such as mineral dissolution at the contacting asperities, that may result in the welding and the annealing of the contacts, were active, the post-holding shear stress would increase compared with the pre-holding stress. However, Fig.3 shows that the post-holding shear stress is lower than the pre-holding stress. Based on the experimental results for the granite specimen, it may be concluded that there is no shear strength recovery or change in aperture. This may be attributed to that the fact that the applied stress level is so low compared with the material strength $\left(\sigma_{n} / \sigma_{c}=1 / 171\right)$, and that the duration of the hold shearing is so short. Consequently, it is thought that chemo-mechanical effects are not markedly activated.

\subsection{Specimen M-1}

For the granite specimen, the shear strength recovery was not clearly observed. As mentioned above, one of the reasons is the relationship between the material strength and the confining stress condition. Thus, using the mortar replica specimen with a uniaxial compressive strength of 40.0 MPa, which is less than $1 / 3$ of the granite strength, SHS direct shear-flow coupling experiments have been carried out at the same normal confining pressures of 1.0 and 5.0 MPa. Fig.5 shows an enlarged view of the shear stress curves obtained through SHS direct shear-flow coupling experiments on M-1. Here, Case-1 is the simple direct shear experiment. On the other hand, Cases-2 and -3 are those of the holding of the shear displacement before and around the peak shear strength. As the shear before the peak shear strength is held (Fig.5(a)), the shear behavior after the holding is likely to move back to the original curve, implicating that no strength recovery occurs. In contrast, as the shear is held at the peak strength, a larger strength is measured after the holding (Fig.5(b)). The strength recovery is relatively small (i.e., roughly $0.3 \mathrm{MPa}$ greater than that of $\mathrm{M}-1$ for which there is no shear holding around the peak strength), but that is apparent.

Changes in dilation and transmissivity with time, before and around the peak shear strength, are shown in Fig.6. For both cases, the measured dilations are almost constant throughout the measurements and the transmissivity monotonically decreases with time. The reduction in 
transmissivity may represent the closure of a fracture’s aperture during the holding time.

Based on Figs.5 and 6, we can find a reduction in shear stress in all cases during the holding period. Shear strength recovery under a normal confining stress condition of 1.0 MPa can be clearly confirmed. However, the reduction in hydraulic conductivity can be found only during the holding period. Consequently, it is thought that for the mortar specimen under a normal confining stress of 1.0 $\mathrm{MPa}$, the chemo-mechanical processes may be active during the holding time and the effect may anneal the contacting asperities within a fracture. This may cause the strength recovery measured after the holding at the peak shear strength.

\section{3-3 Specimens M-2 and M-3}

Fig.7(a) shows the relation between the shear displacement - shear stress dilation curves for M-2 (i.e., a normal confining pressure of $5 \mathrm{MPa}$ ). Fig.7(b) presents an enlarged view of the shear displacement - shear stress curve for Case-3. From the results for Case-3, for shear holding around the peak shear strength, the evolution of shear strength recovery is clearly confirmed. From the results for Cases-2 and -3 for shear holding at the residual stress state, the evolution of shear strength recovery is also apparent at all points where the shear displacement is held and the magnitude of the shear strength recovery increases with an increase in the time of shear holding.

In this case, the normal confining stress condition, 5.0 MPa, is greater than that of G-1 or M-1. Therefore, the stress exerted over the contacting asperities is also greater and this may enhance the chemo-mechanical effects, likely resulting in more shear strength recovered after the holding time.

The results of the SHS direct shear experiments on the smooth surface fracture, specimen M-3, are shown in Fig.8. In this series, the parameters under discussion are the normal confining stress condition and the moisture condition on the fracture. From all cases in Fig.8, the evolution of the shear strength recovery is confirmed at all points where the shear displacement is held and the holding time dependency on the shear strength recovery is also confirmed.

3-4 Discussion of the holding time dependency on the shear strength recovery

For the experimental results of the relatively higher confining stress conditions of specimens 
M-2 and M-3, the holding time dependency on the shear strength recovery can be confirmed. In this section, we will discuss the holding time dependency on the shear strength recovery. According to previous research works $[13,14]$, it is thought that the evolution of the shear strength recovery occurred due to the change in the coefficient of friction on the rock fracture surface since the contact area within the rock fracture was increased by the plastic and/or the visco-plastic deformation of the rocks and the consolidation of the gouge. Then, it was also proposed as the relationship between the holding time and the shear strength recovery, as follows: $\tau_{s}=\tau_{0}+A \log _{10} t_{h}$

where $\tau_{s}, \tau_{0}, t_{h}$, and $A$ are the peak shear strength at the post-holding, the shear stress at the pre-holding, the holding time, and the constant value, respectively. $A$ is the key parameter to estimate the shear strengthening in considering the effects of both normal stress and material strength of intact part. In this research work, the shear strength recovery is defined as the difference between $\tau_{\mathrm{s}}$ and $\tau_{0}$. Fig.9 shows the relationship between the shear strength recovery and the holding time for M-2 and M-3. In each case, it is confirmed that the shear stress recovery increases log-linearly with the holding time. In the range of a holding time of less than $10^{4}$ sec, Equation (2) replicates well the shear strength recovery and the holding time relation. Consequently, a good correlation can be confirmed in all cases between Equation (2) and the experimental plots. And, in the case of the dry fracture condition, the experimental results show a good agreement with Equation (2) for the holding time of even more than $10^{4} \mathrm{sec}$. In contrast, for the wet fracture condition, Equation (2) underestimates the actual measurements for the holding time of more than $10^{4} \mathrm{sec}$, which is congruent with the experimental results by Yasuhara et al. [2].

Chester et al. [10] conducted the isostatic compaction experiments at $150^{\circ} \mathrm{C}$ and $34.5 \mathrm{MPa}$ effective pressures. In the shorten compaction time, it was observed that volumetric strain increased linearly with the logarithm under dry and wet conditions. At the longer compaction time in the wet condition, volume strain appeared to increase linearly with logarithm of time and the volumetric strain rate is larger than that in dry condition. Although the shear strength recovery is forced in this 
paper, this tendency is similar with our results. Since relative high confining stresses are applied to the contacted asperities on the fracture, the creep compaction appears in the contacted asperities. Consequently, the shear strength recovery can be observed under room temperature condtion. Moreover, Chester et al. [10] explained the effect of water in the void as the creep compaction and it was thought that the water made an effective role of the chemical reaction. In our research work, the rapidly increment of the shear strength recover under wet condition can be observed after long term holding. Based on Chester, et al. [10] results, it is thought that the chemical reaction is occurred on the contacted asperities.

In Fig.10, Dieterich's A constant value for the regression lines of Equation (2) is plotted against the normal confining stress. From this figure, the dependency of the normal confining stress can be confirmed and constant value $A$ for the wet fracture condition is larger than that for the dry fracture condition. And, constant value $A$ for the rough fracture condition is also larger than that of the smooth fracture condition.

Based on these results, it is confirmed that Dieterich's law can be applied during the relatively short holding period (i.e., $<10^{4} \mathrm{sec}$ ). It is thought that visco-plastic deformation occurs in the contact area, and that the cohesion and the contact area increase as mediated by a chemo-mechanical effect. The time-dependency on the shear strength recovery increases in the cases of a high normal confining stress and a wet fracture condition. Both the normal confining stress and the wet condition accelerate chemical reactions, and the contact area may increase more rapidly. In the dry facture condition, it is also thought that the visco-plastic deformation in the contact area mainly controls the shear strength recovery. In the long term holding under the wet condition, Dieterich's law cannot be applied. It is thought that the chemical reaction should be enhanced by water and applied pressure, and that the shear strength recovery becomes greater than the regression line of Dieterich's law. With such a long holding time period and under the wet fracture condition, the chemo-mechanical coupling processes should be measurable and have domination over the typical shear behavior represented by the Dietrich’s law. 
This outcome gives significant implications as we consider the important engineering issue of the underground deposits of high-level radioactive waste. As mentioned in Section 3.2, no strength recovery was measured for M-1 (i.e., the granite specimen). This is likely to be because the pressure applied is relatively low compared with the strength of the rock itself. Therefore, where relatively high levels of stress are exerted (e.g., deep underground where a high-level radioactive disposal facility is constructed), the chemo-mechanical effects measured in the simulated mortar specimens may be active even for crystalline hard rock like granite. This suggests that further investigations are needed for such hard rock to in order examine when and how the effects influence the hydraulic and the mechanical properties of the fractured rock of interest.

\section{Simulation and discussion of shear strength recovery}

In this chapter, an analytical model of the SHS direct shear experiments will be proposed based on the shear mechanical model of a single fracture $[16,17]$. Simulations of the SHS direct shear experiments are conducted using the proposed model, and the validity of the proposed model is discussed. Moreover, simulations of various experimental conditions are also conducted. The propose of this simulation is to clarify the relationship between the geometrical aperture change and the shear strength recovery.

\subsection{Model}

The shear mechanical model utilizes the discrete data on the surface roughness obtained through the profiling technique, as mentioned in the section on the experiments. The model is capable of simulating the shear behavior of rock joints, such as the variation in shear stress, the dilation angle, and the dilation of the entire specimen. Moreover, it can simulate the geometry of the surface roughness at different stages of the shearing process. The Appendix provides an outline of the shear mechanical model.

When the shear mechanical model is applied to the SHS direct shear experiments on a single fracture, we must consider the process of shear holding. In Fig.6, the closure of an aperture may be 
confirmed by the reduction in hydraulic conductivity. The relation between the geometrical aperture and the contact-area ratio may be constrained by the digitized fracture data obtained by profilometry. The relation is approximated by the regression curve [8]. Then, the relation between dilation and the holding time in the case of M-2, Case-3, is shown in Fig.11, since in this case, Case-3 was clearly confirmed as the shear strength recovery. From Fig.11, the reduction in dilation, that is, the increment in the compressive deformation of the rock fracture during the shear holding can be confirmed. This may result from the visco-plastic deformation of the contacted asperities. The relation is approximated by the regression curve. In this research work, the following approximation curve is defined to follow the experimental results in Fig.11.

$\Delta d=a \log _{10} t_{h}$.

In this equation, $\Delta d$ and $a$ are the change in dilation and the constant value, respectively. From Fig.11, $a$ is determined to be 2.33 .

The procedure for the model predictions is as follows. First of all, the initial aperture distribution is set to match the average initial aperture measured in the experiments. Then, a shear displacement is prescribed by the mechanical shear model. The model predicts the shear stress and the dilation evolved with the shear displacement. Next, in the holding process, the roughness geometry at the upper side of the rock fracture moves down along the vertical direction with time by following Equation (3). When the roughness geometry moves down, overlapping points appear. In this case, new coordinates are decided, namely, the middle point of the overlapping upper and lower factures is set in contact and the coordinate will be a modified datum for both the upper and the lower surfaces, which is explained in the Appendix. After the holding process, the shear process is simulated again.

\subsection{Simulation results}

The parameters utilized for the shear mechanical model, namely, the uniaxial compressive strength and the basic friction angle, are shown in Table 1. First of all, the case of M-2, Case-3, is simulated. In this case, the shear holding is prescribed at the shear displacement of $2.2 \mathrm{~mm}$. From 
previous research works $[16,17,24]$, the peak shear strength and the residual stress of the simulation were in good agreement with the experimental results. In this case, we can obtain the good correction results between the experimental results and the simulations. Fig 12 show the simulation results as focused on the slide-hole-slide process. At the shear displacement of $2.3 \mathrm{~mm}$, that is, the post-holding shear displacement, the shear stress recovery can be found from the simulation results. However, the stress reduction during the holding period cannot be simulated.

Here, the $\tau_{s}-\tau_{0}$ in the simulation is defined as the difference between the shear stress in the case of no holding and the shear stress of each holding case in the post-holding shear process. Fig.13 shows the relationship between the shear strength recovery and the holding time for M-2, Case-3. In Fig.13, the experimental results are also shown. From Fig.13, the shear strength recovery in the simulation can be confirmed to increase with increments in holding time; this is the same tendency as in the experimental results. A constant value for Dieterich's law is determined as $5.00 \mathrm{X}$ $10^{-2}$ from the regression line of Equation (2), which is almost equivalent to the experimental value. Based on these results, the proposed simulation model can express, with relatively good accuracy, the healing of the shear strength of a single rock fracture within a holding period of $10^{4}$ sec. In other words, the contact area of a rock fracture increases with the time-dependent reduction of the dilation, as shown in Equation 3. After the holding period, it is thought that the shear strength recovery can be found in the process of the re-shearing.

During long holding periods, such as over 2 weeks, on the other hand, the rapid increment in shear strength recovery cannot be simulated. The experimental results for holding periods of over 2 weeks greatly exceed Dietreich’s law. However, the simulated results still show a good agreement with Dietreich's law. This is because the proposed model, based on the mechanical shear model, only takes into account the influence of the creep deformation at the contacting asperities; it does not account for chemo-mechanical effects such as the welding and the annealing of the contacting asperities, which are measured in the experiments.

\subsection{Implications}


As mentioned above, the proposed model can be confirmed to simulate the healing of the shear strength until a holding period of 2 weeks. The experiments have not been carried out under various normal confining stresses. Using the proposed model, applied to specimens G-1 and M-2 in this section, the healing of the shear strength is simulated under various normal confining stresses, and the relationship between the constant value of Dieterich's law, $a$, and the normal confining stress is discussed.

Fig.14 shows the relationship between the shear strength recovery and the holding time for G-1 and $\mathrm{M}-2$. In each case, it is confirmed that the shear strength recovery increases with increments in the holding period. And, under a low normal confining stress, it is also confirmed that the shear strength recovery and the increment in shear strength recovery are small. In our experimental work on G-1 and M-1, we could not obtain shear strength recovery in the process of SHS. This is the reason why, under a low confining stress, the shear strength recovery could not be clearly detected in the experimental observations. Fig.15 shows the relationship between the constant value of Dieterich's law, $a$, and the normal confining stress. In each specimen, the normal confining stress dependency of the constant value, $a$, can be confirmed. Constant value, $a$, of the higher compressive strength specimen, G-1, is larger than that of the lower compressive strength specimen, $M-2$, in the range of normal confining stress of more than 3.0 MPa. However, in the range of low normal confining stress, of less than 1.0 MPa, the influence of the material strength can be disregarded.

\section{Conclusions}

Shear-hold-shear direct shear-flow coupling experiments on rock fractures have been carried out, and the chemo-mechanical effects which evolved from them have been discussed. Under relatively highly confining stresses, the increment in shear strength recovery has been confirmed for each experimental result. Moreover, under the wet condition of the fractures, the magnitude of the shear strength recovery has been found to increase. Until a holding time of $10^{4}$ sec, the shear strength recovery and the holding time relation have shown a good correlation with the regression 
line obtained by the log-linear representation defined by Dietrich [14]. In this time range, it is thought that the creep deformation of the contacted asperities seriously influences the shear behavior and may result in an increase in the contact area. Consequently, the shear strength recovery is measured. On the other hand, with a long holding period and under the wet condition of the fractures, the chemical reaction may be active and the cohesion and the growth of the contacted area may be enhanced. Therefore, the rapid rate of the shear strength recovery is measured in the experimental results.

The modified mechanical shear model has been applied to simulate the SHS direct shear experiments on rock fractures. The simulation results can present a good agreement with the experimental results until a holding time of $10^{4}$ sec. However, the reduction in stress during the holding period cannot be simulated by the proposed model, nor can the rapid rate of the shear strength recovery with a holding time of more than $10^{4}$ sec be predicted. The proposed model, which is based on the mechanical shear model, considers nothing but the influence of creep deformation on the contact asperities. Thus, it can express only the phenomenon of the healing of the shear strength.

From the experimental results, the change of the hydraulic conductivity was slightly observed. In some cases, the change of the hydraulic conductivity could not be observed although the shear strength recovery has appeared. The relationship between the change of aperture distribution and the change of hydraulic conductivity within the holding time cannot be clearly explained. On the other hand, considering the change of fracture geometry condition as the logarithm with time, the shear strength recovery can obtained through the mechanical shear model. Using the change of fracture geometry condition, the flow through simulation will be carried out and the validity of the change of aperture condition will be discussed.

\section{Acknowledgements}

This work was supported by the Grant-in-Aid for Scientific Research(C) No. 20560460. We are 
also grateful to Dr. Takao Yano for his kind support of our experimental work.

\section{References}

[1] Tenthorey E, Cox SF, Todd HF. Evolution of strength recovery and permeability during fluid-rock reaction in experimental fault zones. Earth Plan Sci Lett 2003;206:161-172.

[2] Yasuhara H, Marone C, Elsworth D. Fault zone restrengthening and frictional healing: The role of pressure solution. J of Geophysical Research. 2005;110:B6 B06310.

[3] Weyl PK. Pressure solution and the force of crystallization-A phenomenological theory. J of Geophysical Research. 1959;64(11):2001-2025.

[4] Rutter EH. The kinetics of rock deformation by pressure solution. Philos Trans R Soc London Ser A. 1976;283:687-692.

[5] Raj R. Creep in polycrystalline aggregates by matter transport through a liquid phase. J of Geophysical Research. 1982;87:4731-4739.

[6] Revil, A. Pervasive pressure-solution transfer: A poro-visco-plastic model. Geophysical Research Letters. 1999;26(2):255-258.

[7] Beeler NM, Hickman SH. Stress-induced, time-dependent fracture closure at hydrothermal conditions. J of Geophysical Research. 2004;109:B02211.

[8] Yasuhara H, Elsworth D, Polak A. Evolution of permeability in natural fracture: Significant role of pressure solution. J Geophysical Research 2004;109(B3): B03204.

[9] McDermott C, Kolditz O. Geomechnical model for fracture deformation under hydraulic, mechanical and thermal loads. Hydrogeology Journal 2006;14:485-498.

[10] Chester FM, Chester JS, Kronenberg AK, Hajash A. Subcritical creep compaction of quartz sand at diagenetic conditions: Effects of water and grain size. J Geophysical Research 2007;112:B06203.

[11] Niemeijer A, Marone C, Elsworth D. Healing of simulation fault gouges aided by pressure solution: Results from rock analogue experiments. J of Geophysical Research. 2008;113:B04204. 
[12] Min KB, Rutqvist J, Elsworth D. Chemically and mechanically mediated influences on the transport and mechanical characteristics of rock fractures. Int J Rock Mech Min Sci 2009;46:80-89.

[13] Dieterich JH. Time-dependent friction in rocks. J of Geophysical Research 1972;77:3690-3697.

[14] Dieterich JH. Modeling of rock friction: 1. Experimental results and constitutive equations. J Geophysical Research 1974;84:2161-2168.

[15] Dieterich JH. Direct observation of frictional contacts; New insights for state-dependent properties. Pure Applied Geophysics 1994;243:283-302.

[16] Kishida K, Adachi T, Tsuno K. Modeling of the shear behavior of rock joints under constant normal confining stressess. In: Rock Mechanics in the National Interest. D Elsworth et al., eds. Balkema, 2001, pp 791-798.

[17] Kishida K, Tsuno K. The modeling of the shear behavior of rock joints in consideration of the material friction and the joint surface roughness. J Geotechnical Engineering, JSCE. 2001;680/III-55;245 - 261. (in Japanese)

[18] Ohnishi Y, Yano T, Iwamoto H, Nishikawa N. The history of the research and development of the apparatuses measuring both the shear strength and the roughness profile of rock joints. $\mathrm{J}$ Geotechnical Engineering, JSCE. 2000;645/III-50:307-320. (in Japanese)

[19] Barton N. Review of a new shear strength criterion for rock joints. Engineering Geology. 1973;7(4):287-332.

[20] Barton N, Choubey V. The shear strength of rock joints theory and practice. Rock Mechanics. 1977;10:1-65.

[21] Tse R, Cruden DM. Estimating joint roughness coefficients. Int J Rock Mech Min Sci \& Geomechanics Abs 1979;16:03-307.

[22] Yano T, Ohnishi Y, Nishiyama S, Saito R. Experimental study of shear-flow coupling characteristics of single joints in rock masses. $\mathrm{J}$ Geotechnical Engineering, JSCE 2005;792/III-71:159-174. (in Japanese)

[23] Bandis SC, Lumsden AC, Barton N. Fundamental of Rock Joint Deformation. Int J Rock Mech 
Sci Geomech Abstr 1983;20(6):249-268.

\section{APPENDIX}

In this section, an outline of the mechanical shear model is given.

\section{Outline}

First of all, it is assumed that shear behavior starts at perfectly engaged conditions of the rough joint surface. In this case, the concentration of stress occurs on the asperities which have very large angles. If the asperities have never been shaved, shear behavior appears with dilation angles that are as large as the asperity angles. However, when the asperities are shaved, they are shaved without supporting the concentrated stress because the number of asperities with large angles is very small.

During the initial phase of the shear process for rock joints, the asperities with larger angles control the shear behavior of the rock joints. However, the asperities with larger angles are shaved because the concentration of stress occurs. Then, the asperities with smaller angles gradually come into contact. The dilation angles decrease, and at the same time, the contact area grows and the effective stress for each asperity decreases. It is thought that dilation angles can be determined when the stress acting on the asperities does not occur to yield the asperities.

The normal confining stress in the shear process acts intensively on the contacted asperities. On the other hand, each point contacted on the rock joints depends on both the dilation angle and the shape of the joint surface roughness. If the dilation angle is assumed, the concentrated stress working on the contacted asperities can be determined. It is then believed that the dilation angle can be determined under conditions whereby the normal stress working on the contacted asperities is equal to the uniaxial strength of the intact material. Based on this assumption, the authors create an analytical model for the direct shear behavior of rock joints. The model is based on a simple theory and is thought to be applicable to shear behavior under several types of experimental conditions. Initial step of the shear mechanical model

For example, the joint surface roughness is measured at intervals of $0.5 \mathrm{~mm}$. Therefore, each 
step in this model is equal to a $0.5 \mathrm{~mm}$ progress of shear behavior. For example, it is assumed that the joint surface roughness consists of two kinds of asperity angles along the shear direction, i.e., 25 degrees and 35 degrees. If the dilation angle is assumed to be 30 degrees in this case, contact will be made with the 35-degree asperities, but not the 25-degree asperities. In this model, contact will be made only with the asperities whose angles are larger than the dilation angle, and it is assumed that the concentration of stress will occur on these asperities. Normal stress $\sigma_{n}$, working on the contacted asperities, can be calculated as follows:

$$
\sigma_{n}^{\prime}=\sigma_{n} \cdot T / A
$$

where $\sigma_{n}$ is the normal confining stress, $T$ is the total number of asperities on the rock joints, and $A$ is the number of asperities whose angles are larger than the dilation angle. When the dilation angle is assumed at $\theta$, as shown in Fig.A1, the contacted asperities are extracted. Both normal stress $\sigma_{n}{ }^{\prime}$ and shear stress $\dot{\tau}$ work on the contacted asperities, as shown in Fig.A1, and can be separated into vertical stress $P$ and horizontal stress $Q$ against the rock joint. Considering the length of the rock joint, $1 / \cos \theta, P$, and $Q$ are presented as follows:

$$
\begin{aligned}
& P=\left(\tau^{\prime} \sin \theta+\sigma_{n}^{\prime} \cos \theta\right) \cdot \cos \theta \\
& Q=\left(\tau^{\prime} \cos \theta-\sigma_{n}^{\prime} \sin \theta\right) \cdot \cos \theta
\end{aligned}
$$

The following equilibrium equation for the joint is

$$
Q-P \tan \phi_{b}=0
$$

where $\phi_{b}$ is the basic friction angle of the material. Substituting Equations a2 and a3 for Equation a4, the following relationship between $\sigma_{n}^{\prime}$ and $\tau$ is introduced:

$$
\tau^{\prime}=\sigma_{n}^{\prime}\left(\tan \phi_{b}+\theta\right)
$$

Moreover, considering that the ratio for $\sigma_{n}$ and $\sigma_{n}$ ' is equal to that for $\tau$ and $\tau$, the following equation can be introduced:

$$
\tau=\sigma_{n}\left(\tan \phi_{b}+\theta\right) .
$$


Equation a6 presents the same formula as Patton's equation (Patton 1966) which estimates the shear strength of the regular asperity angle model. During the initial stage in our model, Step 1, normal stress $P$ working on the rock joint is calculated using Equations a2 and a5. The dilation angle at Step $1, \theta_{1}$, is determined by comparing normal stress $P$ with the uniaxial compressive strength of the material.

First of all, it is assumed that the dilation angle is $\theta$ degrees. Then, the number of asperities which have larger asperity angles than $\theta$ degrees is counted. After calculating $\sigma_{n}{ }^{\prime}$ and $\tau^{\prime}$ working on the contacted asperities, normal stress $P$ can be determined. $P$ is then compared with the uniaxial compressive strength of the material. If $P$ is larger than the uniaxial compressive strength, the dilation angle will be modified from $\theta$ to $(\theta-0.1)$ degrees. Then, the same process will be repeated until $P$ becomes less than the uniaxial compressive strength. When $P$ decreases to less than the uniaxial compressive strength, dilation angle $\theta_{1}$ is determined at the shear displacement of $0.5 \mathrm{~mm}$. Incorporating the determined dilation angle into Equation a6, the shear stress at a shear displacement of $0.5 \mathrm{~mm}$ can be estimated.

The shape of the joint surface roughness at the end of each step

At the end of each step, the upper part of the specimen moves $0.5 \mathrm{~mm}$ along the shear direction using the determined dilation angle. Before starting Step $n$, the vertical positions of the profiling point $(k, j)$ of the lower specimen and the upper specimen are defined by $X_{n-1}(k, j)$ and $Y_{n-1}(k, j)$, respectively. After finishing Step $n$ (the dilation angle is determined at $\theta_{n}$ ), the new vertical positions, $X_{n}(k, j)$ and $Y_{n}(k, j)$, are obtained as follows:

$$
\begin{gathered}
X_{n}(k, j)=X_{n-1}(k, j) \\
Y_{n}(k, j)=Y_{n-1}(k-1, j)+0.5 \tan \theta_{n} .
\end{gathered}
$$

When the upper and the lower parts of the specimen overlap $\left(X_{n}(k, j)>Y_{n}(k, j)\right)$, it is thought that the specimen comes into contact with the middle point of the overlapping points, and $X_{n}(k, j)$ and $Y_{n}(k$, j) are presented as follows:

$$
\begin{gathered}
X_{n}(k, j)=\left\{X_{n-1}(k, j)+Y_{n-1}(k-1, j)+0.5 \tan \theta_{n}\right\} / 2 \\
Y_{n}(k, j)=\left\{X_{n-1}(k, j)+Y_{n-1}(k-1, j)+0.5 \tan \theta_{n}\right\} / 2 .
\end{gathered}
$$


Step $n$

During and after Step 2, dilation angle $\theta_{n}$ can be determined by applying the same process as in Step 1. In Step $n$, the asperity angle of the joint surface roughness is calculated after finishing Step $n-1$. Then, stress $P$, working on the contacted asperities, is estimated. By comparing $P$ with the uniaxial compressive strength, the dilation angle and the shear stress can be determined at the shear displacement of $0.5 \mathrm{~nm}$. As for the number of contacted asperities, $A$, the weight value $W$ of all the asperities is calculated and $A$ is introduced into sum $W$. The weight value between profiling points $(k-1, j)$ and $(k, j)$ is defined as being either contacted or non-contacted with the upper and the lower parts of the specimen.

First of all, there is a case in which the upper and the lower parts of the specimen make contact with each other at profiling point $(k-1, j)$. If the gradient between profiling points $(k-1, j)$ and $(k, j)$ is larger than the dilation angle, it is defined as $W=1$ because the asperities at this point are contacted. On the other hand, if the gradient is smaller than the dilation angle, it is defined as $W=0$ because of the non-contacted condition.

Next, a case is considered in which neither the upper part nor the lower part of the specimen makes contact at profiling point $(k-1, j)$. A line, whose gradient is $\theta$, is drawn in Fig.A2 from the point of $Y_{n-1}(k-1, \mathrm{j})$ toward the shear direction. The cross point between the broken line and the lower part of the specimen is defined as the TCP (transit contact point). If TCP is located between $X_{n}(k-1, j)$ and $X_{n}(k, j)$, the range from TCP to $X_{n}(k, j)$ affects the shear behavior and $W$ is presented as follows:

$$
W=L / 0.5
$$

where $L$ is the distance between the $x$-coordinates of TCP and $x=k$. The $x$-coordinates of TCP are calculated as follows:

$$
x=\frac{X_{n-1}(k-1, j)-Y_{n-1}(k-1, j)}{\tan \theta-2 X_{n}(k, j)+2 X_{n}(k-1, j)} .
$$

If TCP is not located between $X_{n}(k-1, j)$ and $X_{n}(k, j)$, it is defined as $W=0$.

Predicting the dilation 
After finishing step $n$, namely, the shear displacment is $0.5 n \mathrm{~mm}$, the dilation is calculated using the dilation angles in each step. In other words,

$$
v_{n}=\sum 0.5 \tan \theta_{n}
$$

In this equation, $v_{n}$ is the dilation at the shear displacment of $0.5 n \mathrm{~mm}$ and $\theta_{n}$ is the dilation angle determined in Step $n$. At the end of each step, the variable for the joint surface roughness can be easily grasped because the vertical positioning data for every profiling point can be obtained in each step.

\section{List of Tables and Figures}

Table 1 Material properties of the granite and mortar specimens

Table 2 Experimental conditions

Table 3 Estimation of the maximum closure of the aperture, the initial aperture, and the normal stiffness of the fracture in each specimen through roughness stiffness loading and unloading tests

Fig.1 Contour map of the joint surface roughness.

Fig.2 Outlines of the direct shear tester for a single fracture [18] and the shear box [22].

Fig.3 Experimental results of the slide-hold-slide direct shear experiments on a single fracture in granite.

Fig.4 Dilation and transmissibility plotted against log hold time through a single fracture in granite.

Fig.5 Experimental results of the slide-hold-slide direct shear experiments on a single fracture in specimen M-1. Case-1 is the normal direct shear experiment, and Cases-2 and -3 are the shear hold before and at the peak shear strength, respectively.

Fig.6 Dilation and transmissibility plotted with log holding time.

Fig.7 Shear stress - shear displacement relation and dilation - shear displacement relation for specimen $\mathrm{M}-2$.

Fig.8 Shear stress - shear displacement relation obtained through SHS direct shear experiments on the smooth mortar specimen, M-3. 
Fig.9 Difference between $\tau_{s}$ and $\tau_{0}$ plotted against the log hold time. The log linear regression lines are evaluated for the shear strength recovery. With a wet condition on the fracture, the rapid increment in shear strength recovery is observed over $10^{4}$ hold times.

Fig.10 A constant value for Dieterich’s law plotted against the normal confining stress. Confining stress dependency is observed.

Fig.11 Relationship between dilation and holding time for specimen M-2, Case-3.

Fig.12 Simulation results through the proposed model in the case of specimen M-2, Case-3.

Fig.13 The difference between $\tau_{s}$ and $\tau_{0}$ is plotted against the log holding time obtained through the modified shear mechanical model. The log linear regression lines are evaluated for the shear strength recovery. Over $10^{4}$ holding times, the rapid increment in shear strength recovery in the experimental results cannot be simulated.

Fig.14 The difference between $\tau_{s}$ and $\tau_{0}$ is plotted against the log holding time obtained through the modified shear mechanical model under various normal confining stresses.

Fig.15 A constant value for Dieterich's law is plotted against the normal confining stress obtained through the proposed model. The confining stress dependency is observed and the influence of the material strength can be disregarded in the range of lower normal confining stress conditions.

Fig.A1 Stress on the contacted asperities.

Fig.A2 Concepts of $W$ (weight value) and TCP (transit contact point). 
Table 1 Material properties of the granite and mortar specimens

\begin{tabular}{|c|c|c|c|c|c|}
\hline $\begin{array}{c}\text { Specimen } \\
\text { no. } \\
\end{array}$ & JRC & Material & $\begin{array}{l}\text { Uniaxial compressive } \\
\text { strength [MPa] }\end{array}$ & $\begin{array}{ll}\text { Basic } & \text { fraction } \\
\text { angle }\left[\begin{array}{c}{ }^{\circ} \\
\text { ] }\end{array}\right.\end{array}$ & $\begin{array}{lr}\text { Tangential } & \text { elastic } \\
\text { modulus, } E_{t 50}[\mathrm{MPa}]\end{array}$ \\
\hline G-1 & 33.53 & Granite & 171 & 24.9 & $5.5 \times 10^{4}$ \\
\hline M-1 & 25.17 & \multirow{3}{*}{ Mortar } & \multirow{3}{*}{40} & \multirow{3}{*}{37.2} & \multirow{3}{*}{$4.0 \times 10^{3}$} \\
\hline M-2 & 9.21 & & & & \\
\hline M-3 & Smooth & & & & \\
\hline
\end{tabular}

Table 2 Experimental conditions

\begin{tabular}{|c|c|c|c|c|c|}
\hline $\begin{array}{c}\text { Specimen } \\
\text { no. }\end{array}$ & Case & $\sigma_{n}[\mathrm{MPa}]$ & $\begin{array}{l}\text { Fracture } \\
\text { condition } \\
\end{array}$ & Flow test & Holding period \\
\hline G-1 & - & 1.0 & Wet & Yes & $\begin{array}{l}5 \text { days at the shear displacement of } 2.0 \mathrm{~mm} \\
20 \text { days at the shear displacement of } 2.5 \mathrm{~mm}\end{array}$ \\
\hline \multirow{3}{*}{ M-1 } & Case- 1 & 1.0 & Dry & No & No \\
\hline & Case-2 & 1.0 & Wet & No & \multirow{2}{*}{$\begin{array}{l}3 \text { days before the peak shear strength and } 3 \text { days at } \\
\text { the peak shear strength }\end{array}$} \\
\hline & Case-3 & 1.0 & Wet & Yes & \\
\hline \multirow{3}{*}{ M-2 } & Case- 1 & 5.0 & Wet & No & No \\
\hline & Case-2 & 5.0 & Wet & No & $\begin{array}{l}14 \text { days before the peak shear strength and } 14 \text { days } \\
\text { at the residual stress state }\end{array}$ \\
\hline & Case-3 & 5.0 & Wet & No & $\begin{array}{l}14 \text { days before the peak shear strength and } 60 \text { to } \\
11,500 \text { seconds at the residual stress state }\end{array}$ \\
\hline \multirow{4}{*}{ M-3 } & Case- 1 & 3.0 & Dry & No & \multirow{4}{*}{$\begin{array}{l}60 \text { to } 600 \text { seconds and } 1 \text { day at the residual stress } \\
\text { state }\end{array}$} \\
\hline & Case-2 & 3.0 & Wet & No & \\
\hline & Case-3 & 7.0 & Dry & No & \\
\hline & Case-4 & 7.0 & Wet & No & \\
\hline
\end{tabular}

Table 3 Estimation of the maximum closure of the aperture, the initial aperture, and the normal stiffness of the fracture in each specimen through roughness stiffness loading and unloading tests

\begin{tabular}{l|c|c|c}
\hline \multicolumn{1}{c|}{ Specimen } & G-1 & M-1 & M-2 \\
\hline \hline Maximum closure of the fracture [mm] & $1.94 \times 10^{-3}$ & $4.41 \times 10^{-3}$ & $1.17 \times 10^{-1}$ \\
\hline Initial aperture [mm] & $2.43 \times 10^{-3}$ & $3.81 \times 10^{-3}$ & $4.07 \times 10^{-3}$ \\
\hline Normal stiffness of the fracture [1/MPa] & $2.86 \times 10$ & $7.16 \times 10^{2}$ & $2.26 \times 10$ \\
\hline \hline
\end{tabular}




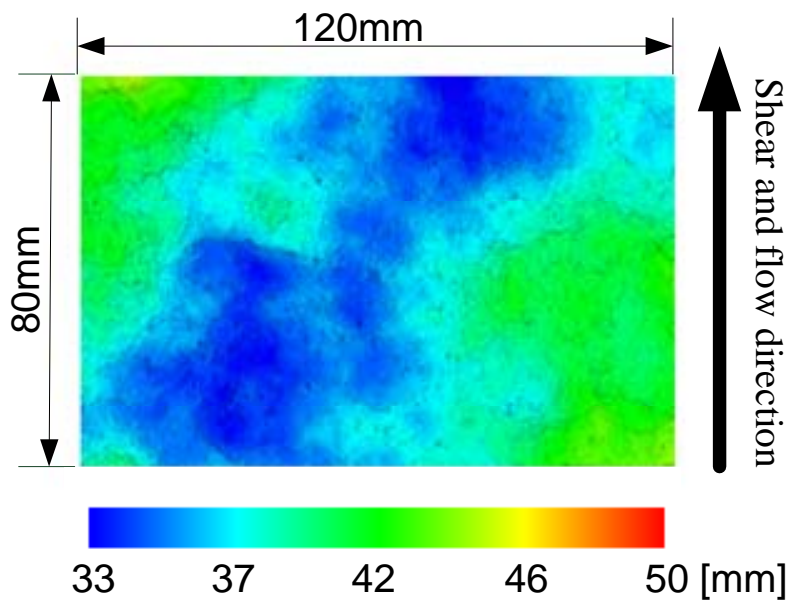

Fig.1 Contour map of the joint surface roughness. Color bar show the altitude from a reference line.(Specimen G-1 and $J R C$ is 33.53).

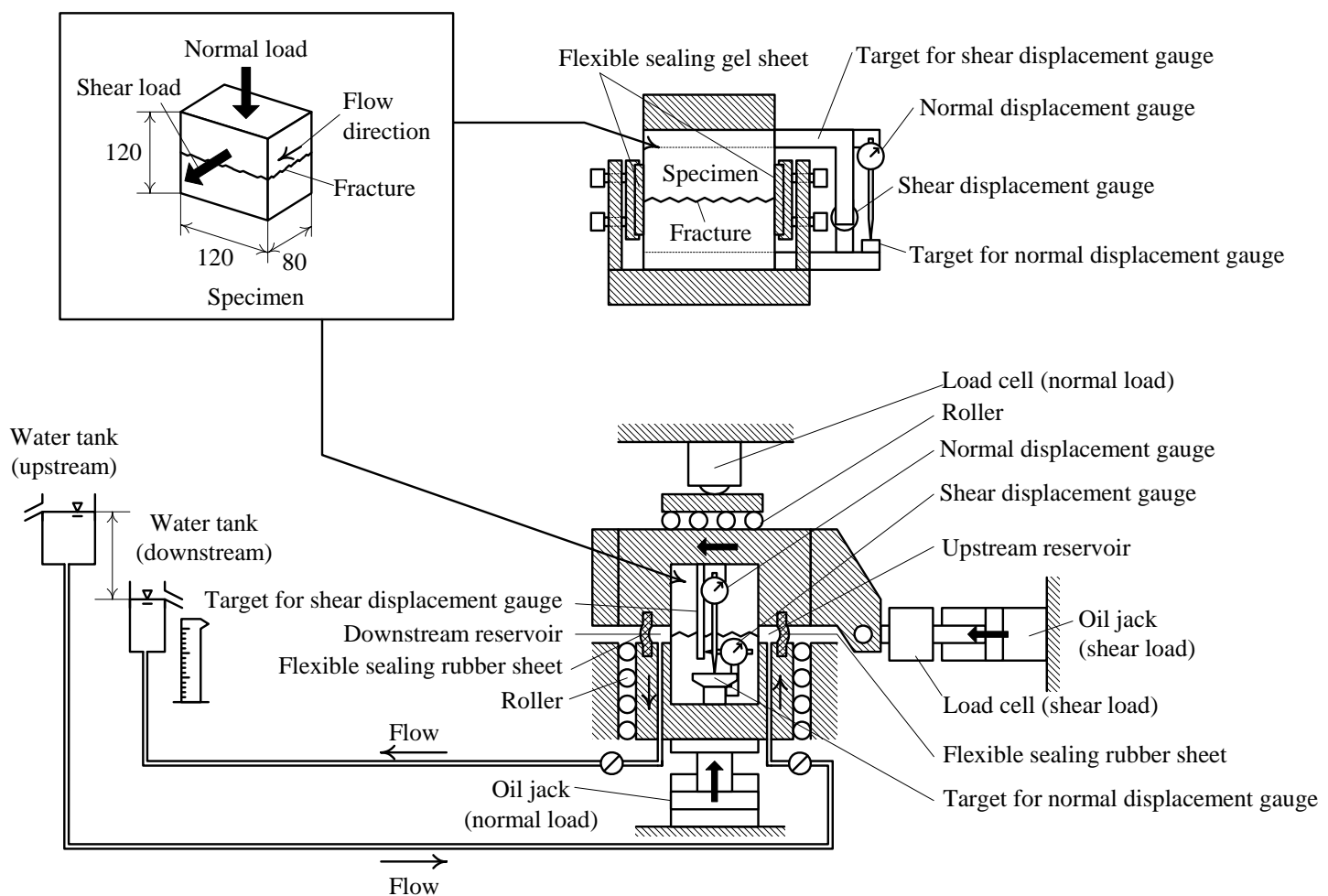

Fig.2 Outlines of the direct shear tester for a single fracture [11] and the shear box [15]. 


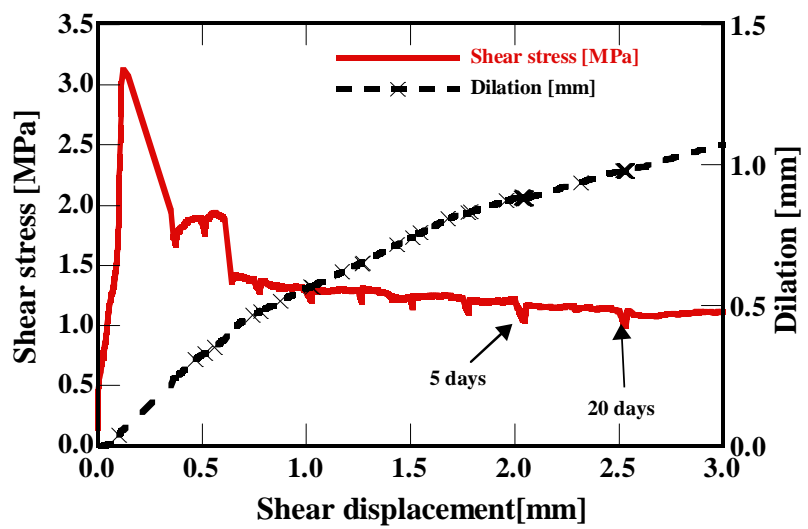

(a) Shear stress - shear displacement relation and dilation- shear displacement relation

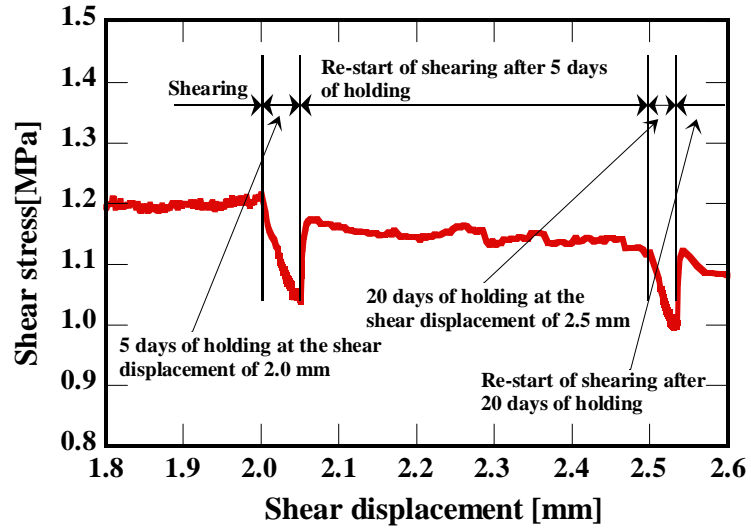

(b) Enlarged view of the shear stress curve around shear displacements of $2.0 \mathrm{~mm}$ and $2.5 \mathrm{~mm}$

Fig.3 Experimental results of the slide-hold-slide direct shear experiments on a single fracture in granite.

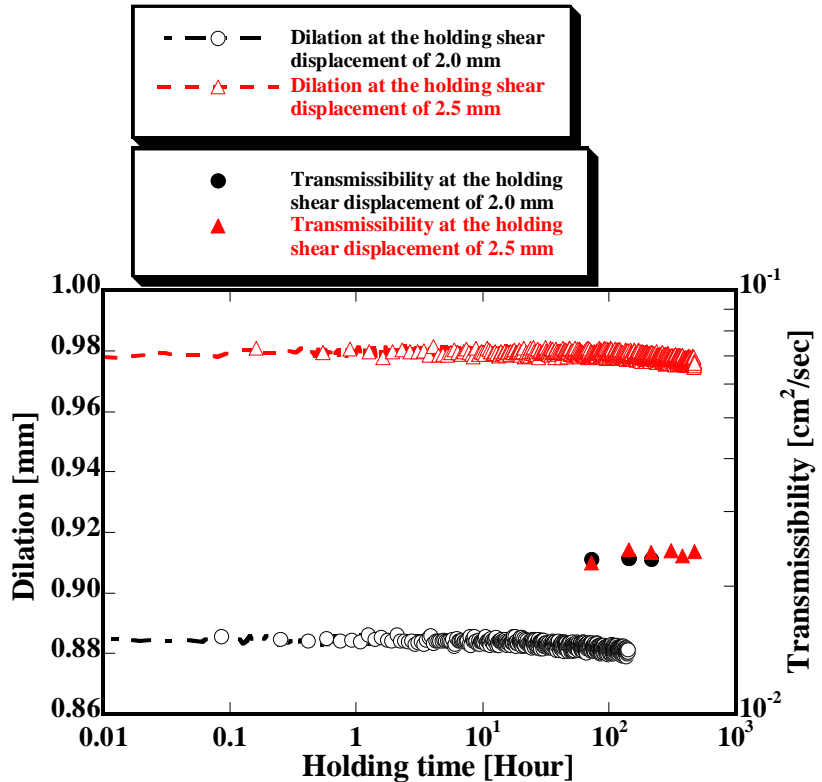

Fig.4 Dilation and transmissibility plotted against log hold time through a single fracture in granite. 


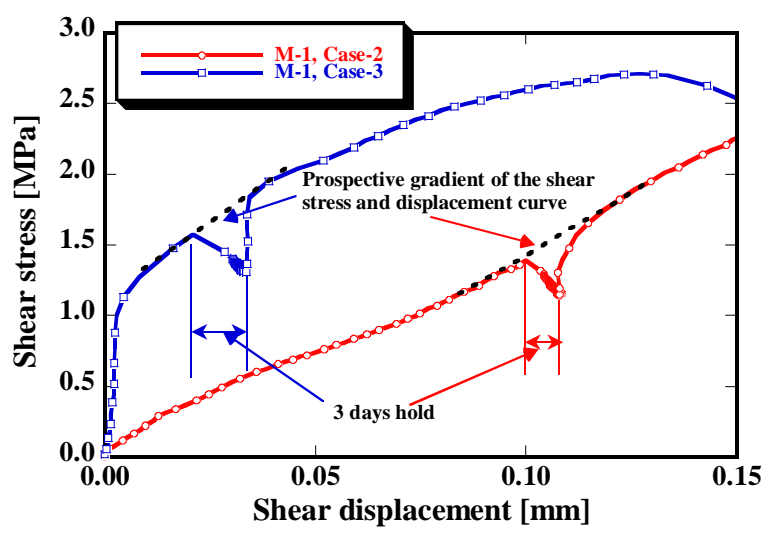

(a) Shear hold before the peak shear strength

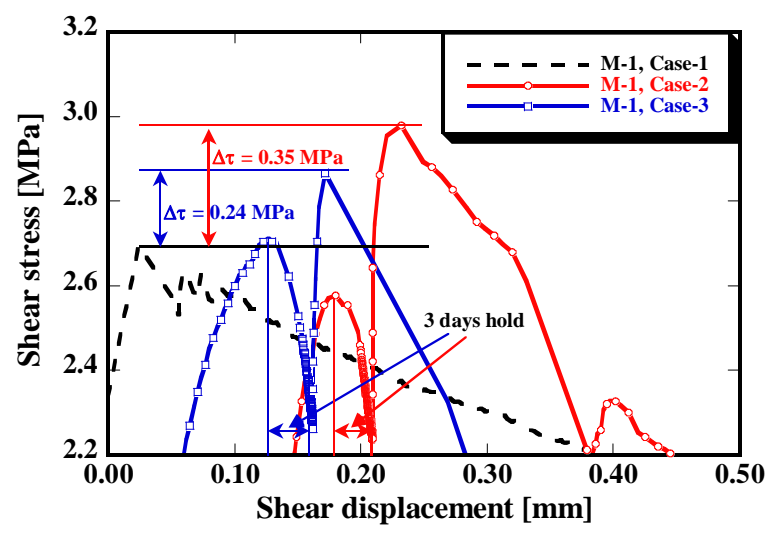

(b) Shear hold at the peak shear strength

Fig.5 Experimental results of the slide-hold-slide direct shear experiments on a single fracture in specimen M-1. Case- 1 is the normal direct shear experiment, and Cases- 2 and -3 are the shear hold before and at the peak shear strength, respectively.

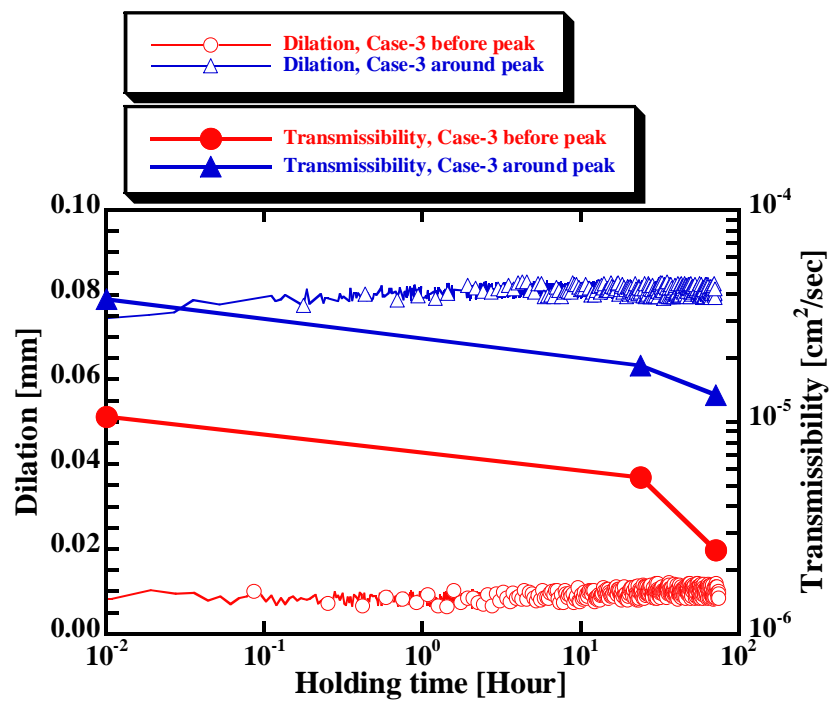

Fig.6 Dilation and transmissibility plotted with log holding time.

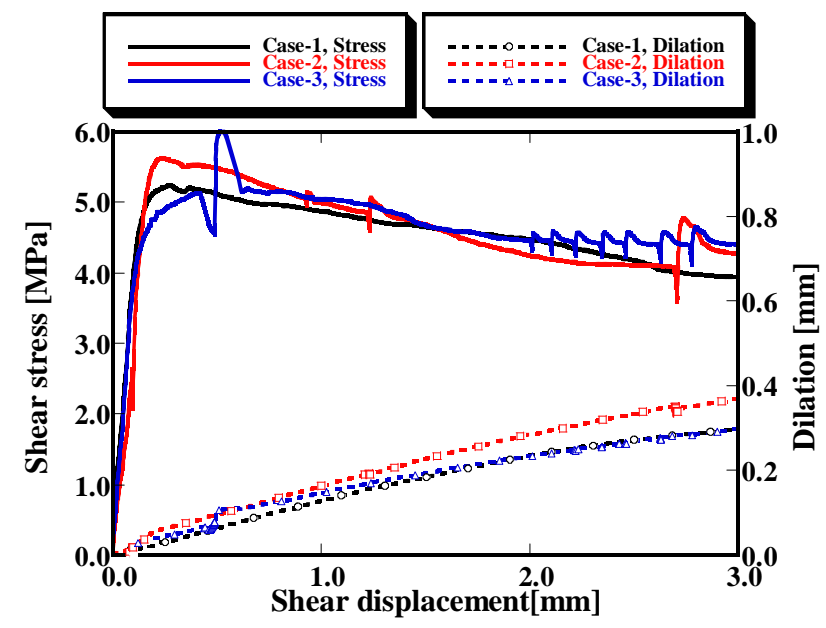

(a) Experimental results 


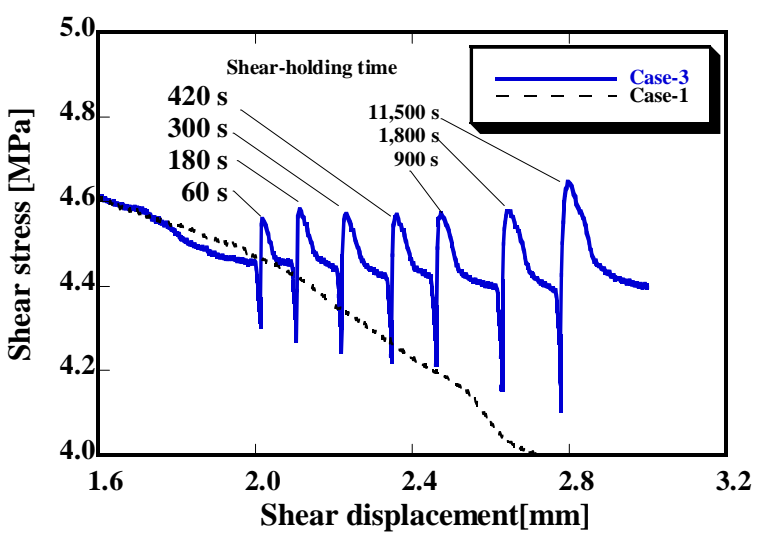

(b) Enlarged view of the shear stress - shear displacement curve around the holding points (Case-3)

Fig.7 Shear stress - shear displacement relation and dilation - shear displacement relation for specimen M-2.

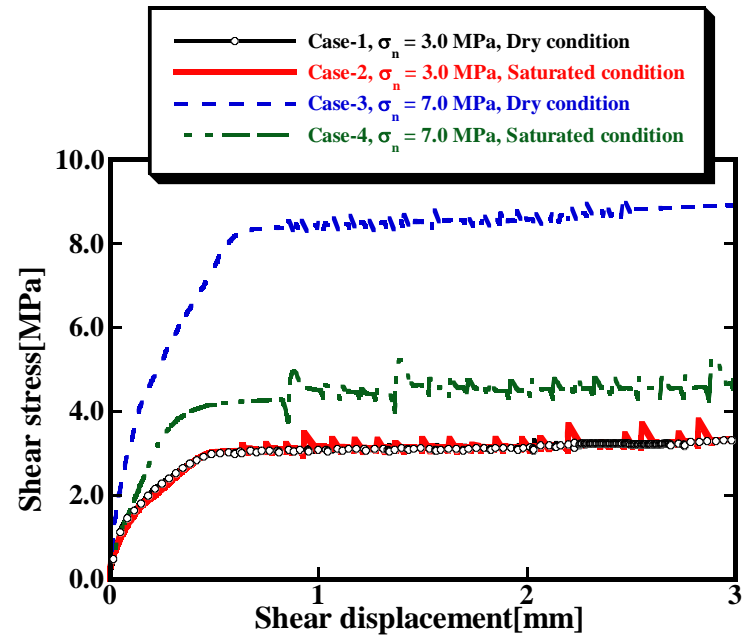

Fig.8 Shear stress - shear displacement relation obtained through SHS direct shear experiments on the smooth mortar specimen, M-3.

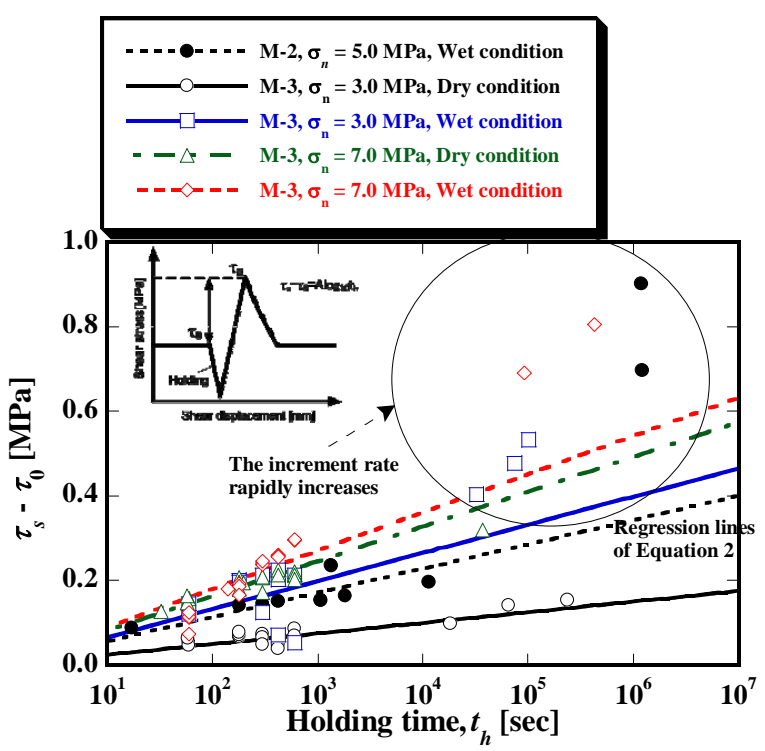

Fig.9 Difference between $\tau_{s}$ and $\tau_{0}$ plotted against the log hold time. The log linear regression lines are evaluated for the shear strength recovery. With a wet condition on the fracture, the rapid increment in shear strength 
recovery is observed over $10^{4}$ hold times.

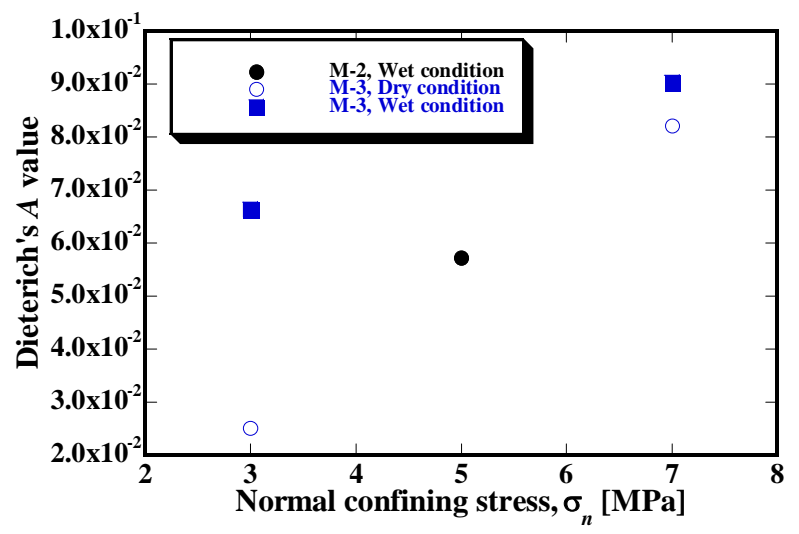

Fig.10 A constant value for Dieterich's law plotted against the normal confining stress. Confining stress dependency is observed.

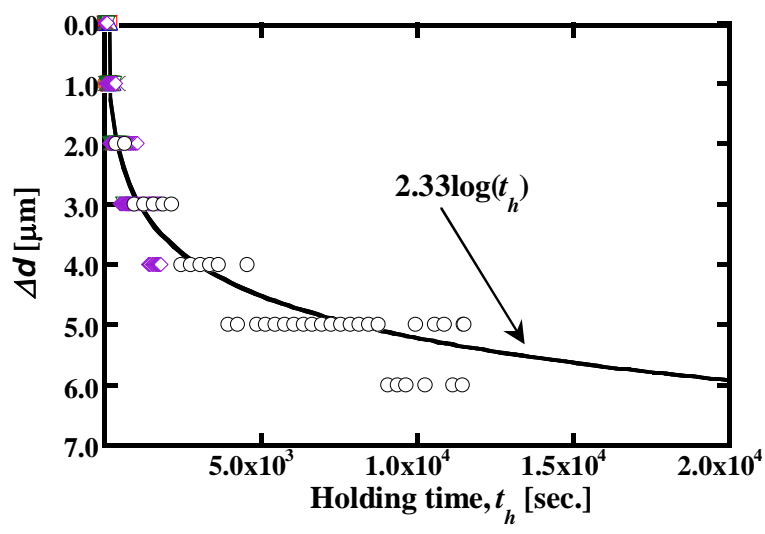

Fig.11 Relationship between dilation and holding time for specimen M-2, Case-3.

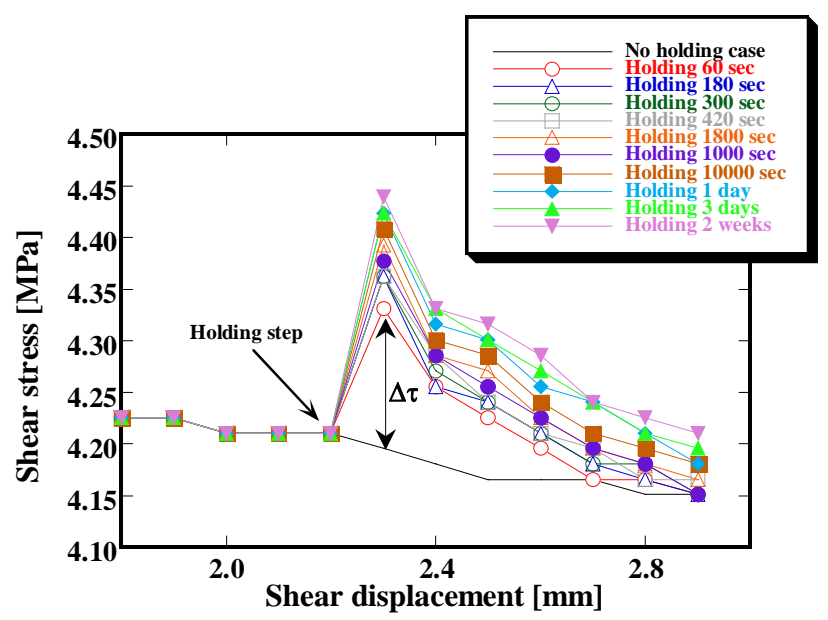

Fig.12 Simulation results through the proposed model in the case of specimen M-2, Case-3. 


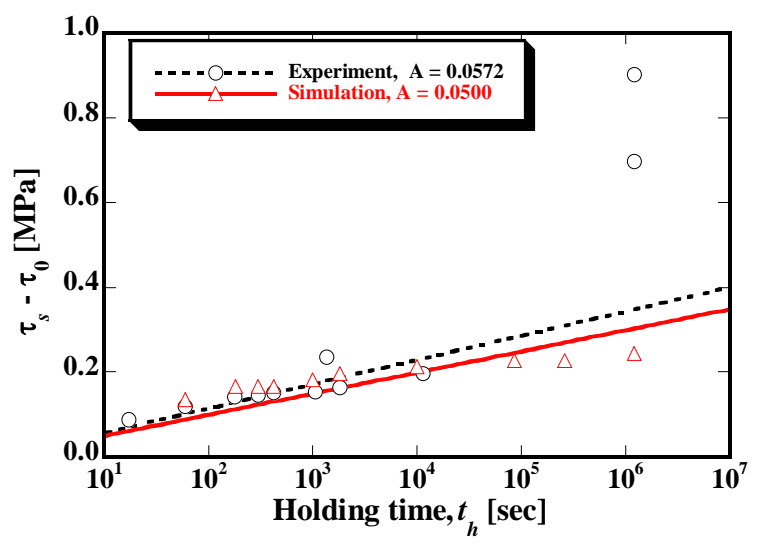

Fig.13 The difference between $\tau_{s}$ and $\tau_{0}$ is plotted against the log holding time obtained through the modified shear mechanical model. The log linear regression lines are evaluated for the shear strength recovery. Over $10^{4}$ holding times, the rapid increment in shear strength recovery in the experimental results cannot be simulated.

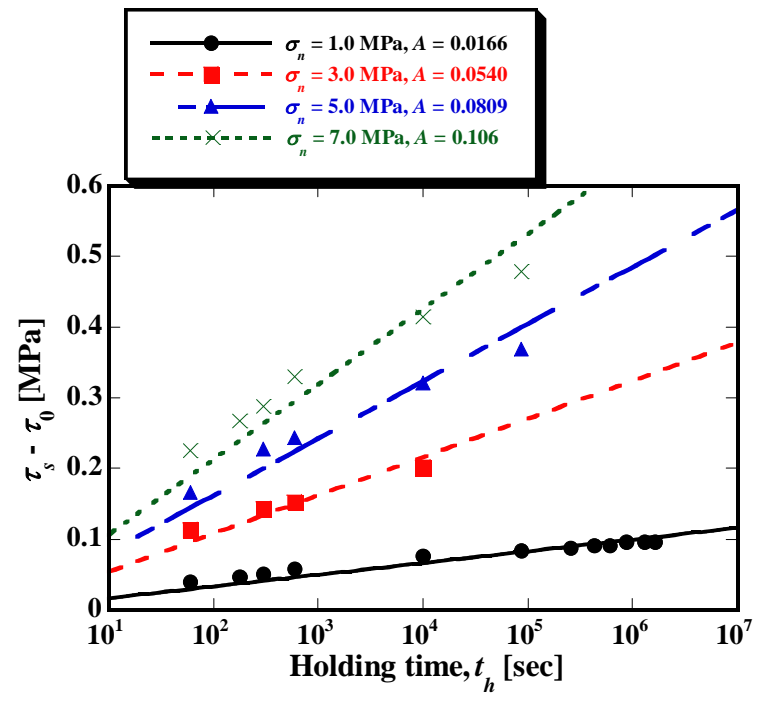

(a) G-1, Granite

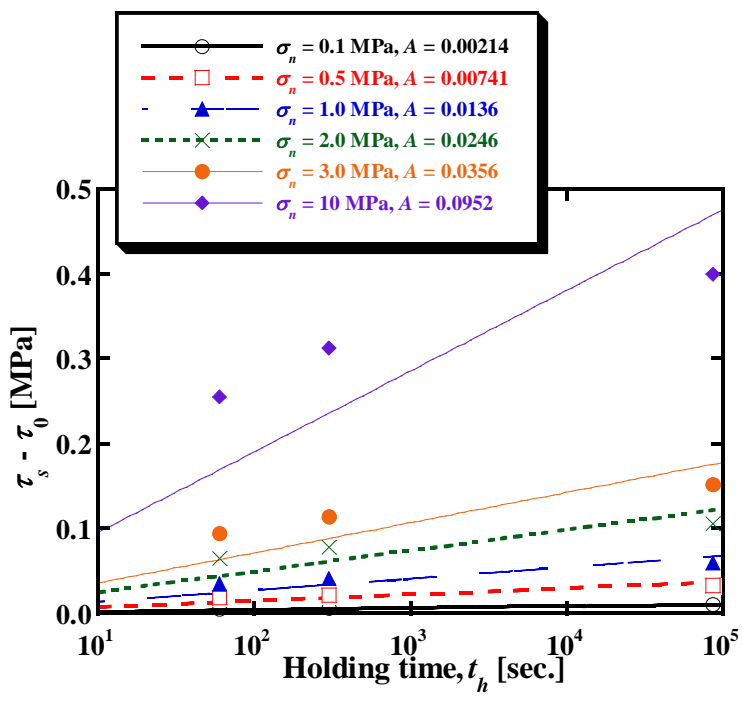

(b) M-2, Mortar

Fig.14 The difference between $\tau_{s}$ and $\tau_{0}$ is plotted against the log holding time obtained through the modified shear mechanical model under various normal confining conditions.

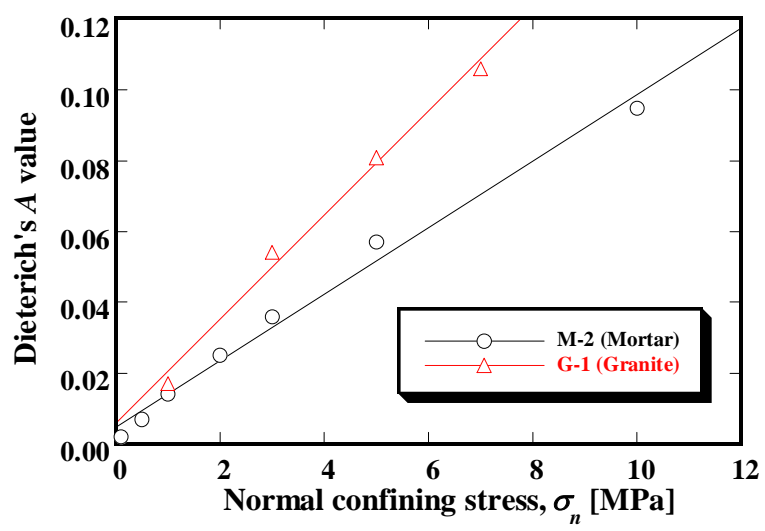

Fig.15 A constant value for Dieterich's law is plotted against the normal confining stress obtained through the proposed model. The confining stress dependency is observed and the influence of the material strength can be disregarded in the range of lower normal confining stress conditions. 

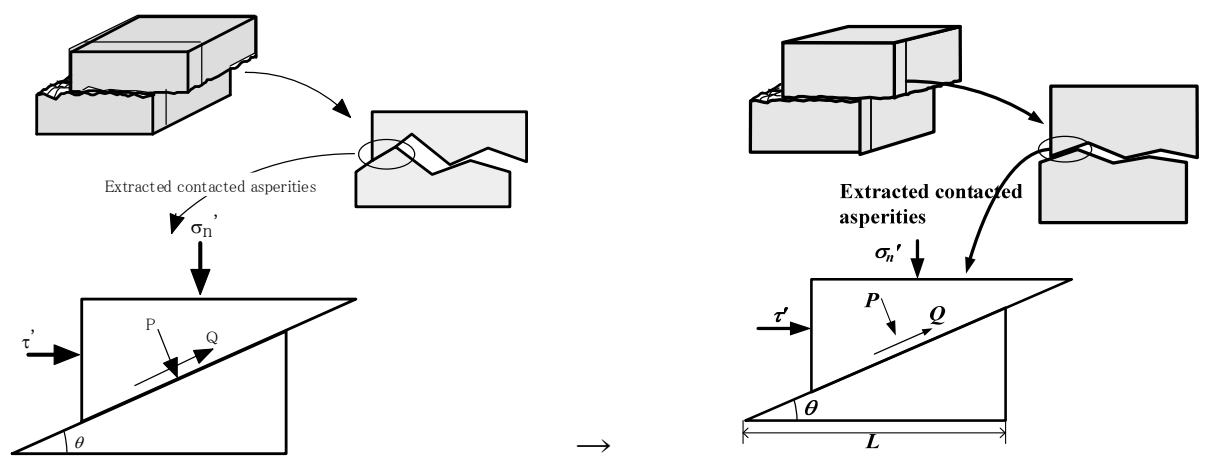

Fig.A1 Stress on the contacted asperities.
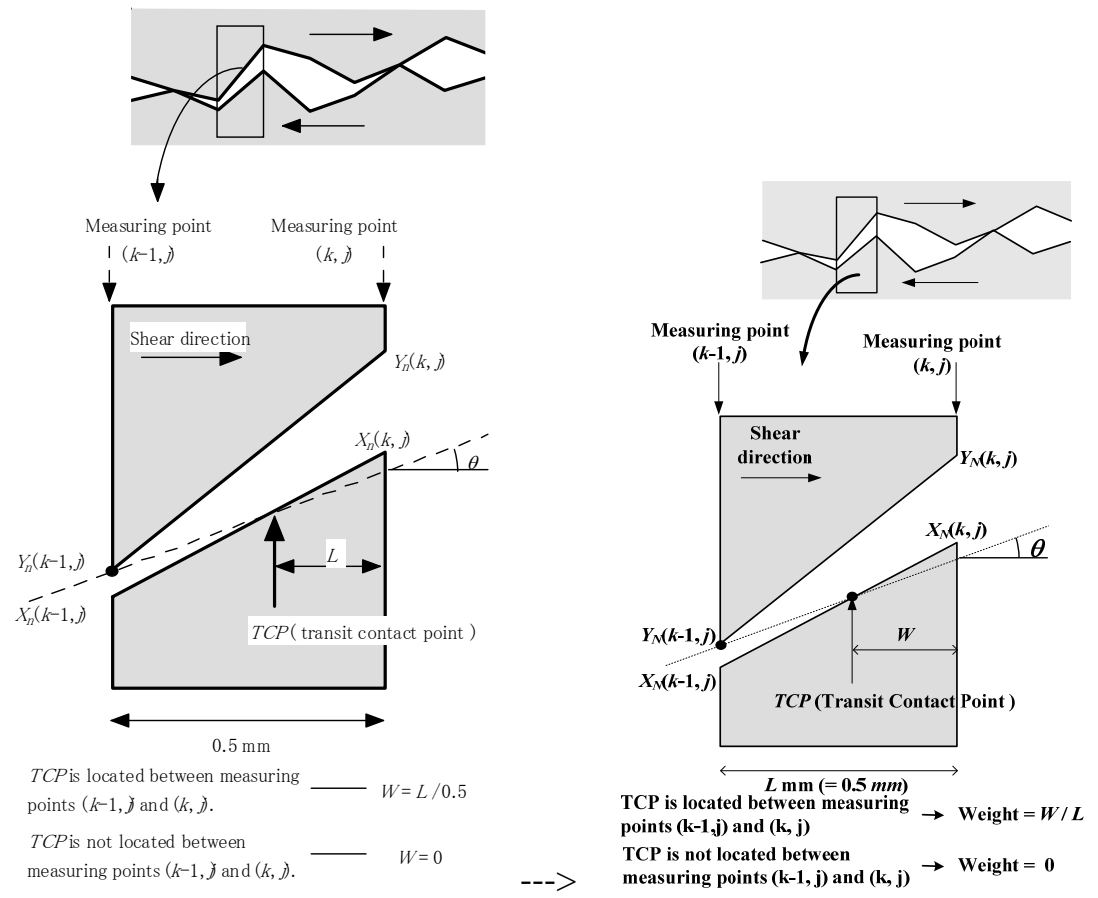

Fig.A2 Concepts of $W$ (weight value) and TCP (transit contact point). 